\title{
A Clinical Study of Pregnancy-Associated Renal Insufficiency
}

\author{
Feng Wang ${ }^{a}$ Tao Xing ${ }^{a, c}$ Niansong Wang ${ }^{a}$ Yajuan Huang ${ }^{b}$ \\ Departments of a Nephrology and b Obstetrics, The Sixth People's Hospital, Shanghai Jiaotong University, \\ Shanghai, China; 'Australian School of Advanced Medicine, Macquarie University, Sydney, N.S.W., Australia
}

\section{Key Words}

Pregnancy $\cdot$ Hypertension $\cdot$ Proteinuria $\cdot$ Renal

insufficiency $\cdot$ Serum creatinine concentration $\cdot$ Chronic

kidney disease $\cdot$ End-stage renal disease $\cdot$ Preeclampsia high among pregnancies with renal impairment. Conclusion: Renal insufficiency associated with pregnancy is not rare, and renal function may deteriorate during the course of pregnancy.

Copyright $\odot 2010$ S. Karger AG, Basel

\begin{abstract}
Background/Aim: This study aimed to explore the causes, incidence and outcome of renal insufficiency during pregnancy. Methods: All pregnant women admitted to our hospital from September 2004 to August 2007 were retrospectively screened for renal function. Patients were divided into 3 groups according to the serum creatinine $(\mathrm{Scr}$ ) level (mild renal insufficiency: Scr 70-123 $\mu \mathrm{mol} / \mathrm{l}$; moderate: Scr 124-220 $\mu \mathrm{mol} / /$; severe: Scr $>221 \mu \mathrm{mol} / \mathrm{l})$. Results: Seventy-five cases (2.51\%) of renal insufficiency were identified. Twenty-two cases $(0.73 \%)$ had evidence of chronic kidney disease before pregnancy. Compared to the moderate and severe groups, the mild group had the lowest blood pressure. In 29 recorded cases with multiple observations throughout pregnancy, the deterioration of renal function progressed during the course of pregnancy; on average, Scr changed from $177 \pm 109 \mu \mathrm{mol} / \mathrm{l}$ in the early phase of pregnancy to $194 \pm 149 \mu \mathrm{mol} / \mathrm{l}(\mathrm{p}<$ $0.001)$ in the third trimester, and mean blood pressure increased from $97 \pm 11$ to $120 \pm 19 \mathrm{~mm} \mathrm{Hg}(p<0.001)$. There were 37 cases with preeclampsia (49\%). Fourteen cases showed a decrease in glomerular filtration rate (GFR) in the third trimester; 4 of these patients suffered a severe decrease in GFR (over 25\%). The rate of obstetrical complications was
\end{abstract}

\section{Introduction}

Significant physiologic mechanisms that alter systemic and renal hemodynamics play an important role in the renal response to changes in fluids and electrolytes during normal pregnancy $[1,2]$. Unique disorders that may result in hypertension and renal disease can occur in pregnancy, and the impact of pregnancy on patients with underlying renal disease has important implications for maternal and fetal morbidity and mortality. Pregnancy-induced hypertension could lead to renal injury and could accelerate the aggravation of intrinsic kidney diseases. This study applied a retrospective analysis of patient data to determine kidney impairment in pregnant patients in the Shanghai Sixth People's Hospital with a view to determining the causes, incidence and outcome of renal insufficiency in order to enhance efforts for the early diagnosis, treatment and prevention of this condition.

T.X. and F.W. contributed equally to this work.

\section{KARGER}

Fax +4161306 1234 E-Mail karger@karger.ch www.karger.com
Prof. Niansong Wang

Department of Nephrology, The Sixth People's Hospital

Shanghai Jiaotong University, 600 Yishan Road

Shanghai 200233 (China)

Tel. +86 216436 9181, Fax +86 216470 1361, E-Mail wangniansong2008@163.com 


\section{Methods}

\section{Subjects}

This study retrospectively analyzed data from all the pregnant women admitted to the Shanghai Sixth People's Hospital, in the departments of nephrology and obstetrics, from September 2004 to August 2008. All patients with a serum creatinine (Scr) concentration above $70 \mu \mathrm{mol} / \mathrm{l}(0.8 \mathrm{mg} / \mathrm{dl})$ at any stage of pregnancy were considered to have abnormal renal function and were included in the study [3]. Scr was used as an index of the glomerular filtration rate (GFR). Renal insufficiency was regarded as mild when the Scr concentration was $70-123 \mu \mathrm{mol} / \mathrm{l}(0.8-1.4 \mathrm{mg} /$ $\mathrm{dl})$, moderate when it was $124-220 \mu \mathrm{mol} / \mathrm{l}(1.4-2.4 \mathrm{mg} / \mathrm{dl})$ and severe when it was $>221 \mu \mathrm{mol} / \mathrm{l}(>2.5 \mathrm{mg} / \mathrm{dl})$ [4]. Renal insufficiency included pregnancy complicated by chronic kidney disease (CKD) and pregnancy-associated deterioration in renal function.

\section{Definitions and Measurements}

We calculated $1 / \mathrm{Scr}$, which correlates linearly with the filtration rate [5], to estimate changes in the GFR in the first and third trimester. Hypertension was defined as a mean arterial blood pressure (MAP) above $105 \mathrm{~mm} \mathrm{Hg}$, with the mean blood pressure calculated as follows: (systolic pressure + diastolic pressure $\times 2$ )/3 [6]. Proteinuria was classified by quantitative or semiquantitative measurements as absent if testing with a dipstick showed no protein or trace levels or if the level was below $300 \mathrm{mg} / 24 \mathrm{~h} \mathrm{[3],} \mathrm{low}$ grade if the dipstick showed a value of $1+$ or $2+$ or the level was $300-3,000 \mathrm{mg} / 24 \mathrm{~h}$, and high grade if the dipstick showed a value of $3+$ or $4+$ or the level exceeded $3,000 \mathrm{mg} / 24 \mathrm{~h}$. The first trimester of pregnancy was defined as the period from the 1st week to the 12 th week. The third trimester was defined as the period after 29 weeks and up to 42 weeks. Preeclampsia was defined as the onset of hypertension and proteinuria after 20 weeks of gestation in previously normotensive pregnant women [7]. Eclampsia was defined as the occurrence of new-onset seizure in a patient with preeclampsia. Kidney disease complicating pregnancy was defined as a history of kidney disease before pregnancy. The definition of CKD was taken from the guidelines published by the $\mathrm{Na}$ tional Kidney Foundation's Kidney Disease Outcomes Quality Initiative [8].

\section{Methods}

The following data were collected from patient records: medical history, blood pressure, results of routine blood and urine examinations, 24-hour urinary protein, results of renal and liver function tests, blood lipids, pregnancy outcome and fetal prognosis, as well as records of treatment protocols.

\section{Statistical Analysis}

All values are presented as means $\pm \mathrm{SD}$. All analyses were conducted using the Statistical Package for the Social Sciences (SPSS 15.0, SPSS, Chicago, Ill., USA). A one-way ANOVA was used for group data, followed by Bonferroni's correction. Paired Student's t test was used to analyze the comparative results. A nonparametric one-way ANOVA was used to compare the Apgar score between the groups, followed by Dunn's correction. For the intergroup constituent ratio, we used the $\chi^{2}$ test and Fisher's exact probability test. Significance was set at $\mathrm{p}<0.05$.

Pregnancy and Renal Insufficiency
Table 1. Basic information for our 75 patients with renal insufficiency

$\begin{array}{lc}\text { Age, years } & 30 \pm 5 \\ \text { First-trimester serum creatinine values available } & 29 \\ \text { History of kidney disease before pregnancy } & 22(29 \%) \\ \text { Serum creatinine, } \mu \mathrm{mol} / \mathrm{l}^{1} & 115 \pm 80 \\ \text { Serum creatinine level } & \\ 70-123 \mu \mathrm{mol} / \mathrm{l} & 57(76 \%) \\ 124-220 \mu \mathrm{mol} / \mathrm{l} & 12(16 \%) \\ >221 \mu \mathrm{mol} / \mathrm{l} & 6(8 \%) \\ \text { MAP, mm Hg } & 110 \pm 22 \\ \text { MAP } \leq 105 \mathrm{~mm} \mathrm{Hg} & 34(43 \%) \\ \text { Antihypertensive therapy } & 9 \\ \text { MAP }>105 \mathrm{~mm} \mathrm{Hg} & 43(57 \%) \\ \quad \text { Antihypertensive therapy } & 30 \\ \text { Proteinuria } & \\ \text { None } & 21(28 \%) \\ \text { Low grade }(300-3,000 \mathrm{mg} / 24 \mathrm{~h}) & 19(25 \%) \\ \text { High grade }(>3,000 \mathrm{mg} / 24 \mathrm{~h}) & 35(47 \%)\end{array}$

Values are means \pm SD or numbers of patients with percentages in parentheses, as appropriate.

${ }^{1}$ To convert values for serum creatinine to milligrams per deciliter, divide by 88.4 .

\section{Results}

During the 3-year study, 2,988 adult pregnant women were hospitalized, all of Han ethnicity, among whom 75 (2.51\%) had evidence of renal insufficiency. Twenty-nine of these 75 patients had Scr and urea measured in the first and third trimester of pregnancy. Renal insufficiency was found to be mild in 57 cases, moderate in 12 cases and severe in 6 cases. In 43 patients, MAP was over $105 \mathrm{~mm}$ $\mathrm{Hg}$, and 39 of these patients took antihypertensive treatment (table 1). Twenty-two patients (29\%) had a history of kidney disease before pregnancy. This group comprised $0.73 \%$ of the total number of pregnant patients admitted during the 3 years of the study. There were 7 cases with documentation of symmetric small kidneys by renal ultrasonography. Renal biopsy revealed 3 cases of primary glomerular disease, 1 case of renal tubular lesion and 1 case of lupus nephritis (type III).

\section{Analysis of Maternal Laboratory Results}

Forty-seven percent of patients had high-grade proteinuria (table 1). The moderate renal insufficiency group had the highest 24-hour urine protein production but there was no statistical significance between the groups $(\mathrm{p}=0.40$; table 2$)$. The group of patients whose 24 -hour 
Table 2. Comparison of laboratory examinations between the groups

\begin{tabular}{llllllc}
\hline $\begin{array}{l}\text { Renal insufficiency } \\
\text { group as } \\
\text { defined by Scr }\end{array}$ & Cases, $\mathrm{n}$ & $\begin{array}{l}\text { Proteinuria } \\
\mathrm{g} / 24 \mathrm{~h}\end{array}$ & Alb, g/l & $\mathrm{TC}, \mathrm{mmol} / \mathrm{l}$ & $\mathrm{TG}, \mathrm{mmol} / \mathrm{l}$ & $\mathrm{Hb}, \mathrm{g} / \mathrm{l}$ \\
\hline Mild & 57 & $3.04 \pm 3.83$ & $33 \pm 5^{*}$ & $6.04 \pm 1.55$ & $2.93 \pm 1.33$ & $113 \pm 15$ \\
Moderate & 12 & $4.64 \pm 3.62$ & $28 \pm 3$ & $6.58 \pm 1.46$ & $6.66 \pm 12.15$ & $109 \pm 21$ \\
Severe & 6 & $3.39 \pm 1.51$ & $28 \pm 2$ & $5.90 \pm 0.90$ & $2.83 \pm 1.16$ & $89 \pm 12^{* *}$ \\
Total & 75 & $3.32 \pm 3.68$ & $32 \pm 5$ & $6.12 \pm 1.49$ & $3.52 \pm 5.03$ & $110 \pm 17$ \\
\hline
\end{tabular}

Values are means $\pm \mathrm{SD}$. Alb = Plasma albumin; TC $=$ total cholesterol; $\mathrm{TG}=$ triglycerides; $\mathrm{Hb}=$ hemoglobin. ${ }^{*} \mathrm{p}<0.05$ compared with the moderate and severe groups; ${ }^{* *} \mathrm{p}<0.001$ compared with the mild group.

urine protein was over $3,000 \mathrm{mg}$ included $40 \%$ of the group with mild renal insufficiency, $58 \%$ of the moderate insufficiency group and $67 \%$ of the severe insufficiency group $(\mathrm{p}<0.05)$. The mean plasma albumin concentration of the patients from the mild renal insufficiency group was statistically greater than that of the other groups ( $\mathrm{p}<0.05$; table 2 ). The mean plasma albumin concentration was not statistically different between the other 2 groups $(p=0.22$; table 2$)$. There was no difference in serum total cholesterol $(\mathrm{p}=0.57)$ or triglycerides $(\mathrm{p}=$ 0.06 ; table 2) between the groups. The mean hemoglobin of the patients with mild renal insufficiency was statistically higher than that of the patients with severe renal insufficiency $(\mathrm{p}<0.001)$. However, there were no statistically significant differences between the mild and moderate and the moderate and severe groups $(\mathrm{p}=0.37$ and $\mathrm{p}=0.06$, respectively; table 2 ).

\section{Analysis of Maternal Blood Pressure}

The systolic pressure, diastolic pressure and MAP of the mild group were statistically significantly lower (all $\mathrm{p}<0.05$; table 3) than those of the moderate and severe groups. There were no differences between the moderate and severe groups (table 3). Among the 3 groups, patients whose mean blood pressure was over $105 \mathrm{~mm} \mathrm{Hg}$ represented $44 \%$ of the mild group ( $\mathrm{Scr}<123 \mu \mathrm{mol} / \mathrm{l}$ ), $92 \%$ of the moderate group (Scr 124-220 $\mu \mathrm{mol} / \mathrm{l}$ ) and $100 \%$ of the severe group $(\mathrm{Scr}>221 \mu \mathrm{mol} / \mathrm{l})$, respectively $(\mathrm{p}<$ 0.05).

\section{Comparison of Renal Function and Blood Pressure in} the First and Third Trimester of Pregnancy

In the current study, there were 29 patients with records of multiple observations from the first and third trimesters of pregnancy. These patients served as a sub-
Table 3. Comparison of blood pressure between the groups

\begin{tabular}{lcccl}
\hline $\begin{array}{l}\text { Renal insuffi- } \\
\text { ciency group as } \\
\text { defined by Scr }\end{array}$ & Cases, n & $\begin{array}{l}\text { SBP } \\
\mathrm{mm} \mathrm{Hg}\end{array}$ & $\begin{array}{l}\text { DBP } \\
\mathrm{mm} \mathrm{Hg}\end{array}$ & $\begin{array}{l}\text { MAP } \\
\mathrm{mm} \mathrm{Hg}\end{array}$ \\
\hline Mild & 57 & $135 \pm 26^{*}$ & $90 \pm 20^{*}$ & $105 \pm 21^{*}$ \\
Moderate & 12 & $165 \pm 18$ & $104 \pm 17$ & $125 \pm 17$ \\
Severe & 6 & $173 \pm 23$ & $112 \pm 8$ & $132 \pm 11$ \\
Total & 75 & $144 \pm 28$ & $94 \pm 20$ & $111 \pm 22$ \\
\hline
\end{tabular}

Values are means $\pm \mathrm{SD} . \mathrm{SBP}=$ Systolic blood pressure; $\mathrm{DBP}=$ diastolic blood pressure. ${ }^{*} \mathrm{p}<0.05$ compared with the moderate and severe groups.

group for further analysis. These patients included all 22 patients (76\%) who had kidney disease before pregnancy, 12 patients (41\%) whose Scr level was below $124 \mu \mathrm{mol} / \mathrm{l}$, 11 (35\%) whose Scr level was between 124-220 $\mu \mathrm{mol} / 1$ and 6 (24\%) whose Scr level was over $221 \mu \mathrm{mol} / \mathrm{l}$. The mean value of Scr increased from $177 \pm 109 \mu \mathrm{mol} / \mathrm{l}$ in the early period to $194 \pm 149 \mu \mathrm{mol} / \mathrm{l}$ in the third trimester of pregnancy $(\mathrm{p}<0.001)$. MAP increased from $97 \pm$ $11 \mathrm{~mm} \mathrm{Hg}$ in the early period to $120 \pm 19 \mathrm{~mm} \mathrm{Hg}$ in the third trimester $(\mathrm{p}<0.001)$. Moreover, before and after the delivery period (induced labor), the incidence of high blood pressure (mean blood pressure $>105 \mathrm{~mm} \mathrm{Hg}$ ) was 24 and 83\%, respectively. Obviously, the incidence of hypertension after delivery was 3 times higher than that before. There were 14 patients (48\%) in whom the GFR $(1 / \mathrm{Scr})$ fell in late pregnancy; in 4 patients it fell severely (over 25\%), and 1 patient entered end-stage renal disease (ESRD) after delivery. 
Table 4. Outcome of infants and neonatal complications

\begin{tabular}{lcc}
\hline & $\begin{array}{l}\text { All patients } \\
(\mathrm{n}=70)\end{array}$ & $\begin{array}{c}\text { Patients with CKD } \\
\text { before pregnancy }(\mathrm{n}=22)\end{array}$ \\
\hline Preterm delivery (<37 weeks) & $36(48 \%)$ & $14(63 \%)$ \\
Delivery by cesarean section & $53(71 \%)$ & $16(72 \%)$ \\
Birth weight, g & $3,048 \pm 853^{1}$ & $2,376 \pm 494^{2}$ \\
Small for gestational age (<10th percentile) & $22(31 \%)^{1}$ & $12(67 \%)^{2}$ \\
Deaths & $7(10 \%)$ & $4(18 \%)$ \\
Stillbirths & 5 & 4 \\
Neonatal deaths & 2 & 0 \\
Admission to neonatal intensive care unit & 20 & 12 \\
Apgar score 3 according to maternal Scr & $8 \pm 2$ & $7 \pm 2$ \\
$70-123 \mu$ mol/l & $9 \pm 2^{*}$ & $8 \pm 2$ \\
$124-220 \mu$ mol/l & $7 \pm 3$ & $5 \pm 1$ \\
$>221 \mu$ mol/l & $5 \pm 1$ & \\
\hline
\end{tabular}

\section{Cases of Preeclampsia}

This study identified 37 cases (49\%) of preeclampsia, of which 24 belonged to the mild group ( $42 \%$ of the group), 7 were in the moderate group (58\% of the group) and 6 were in the severe group. We also analyzed the proportion of patients with $\mathrm{Scr}<123 \mu \mathrm{mol} / \mathrm{l}$ and $>124$ $\mu \mathrm{mol} / \mathrm{l}$. We found that the incidence of preeclampsia was higher in patients with more severe renal insufficiency ( 49 vs. $72 \%$; $p<0.001$ ). The clinical manifestations of these patients were relatively severe, except for ordinary headache, dizziness and edema. One patient suffered intracranial hemorrhage, 3 sustained retinal detachment and 1 patient displayed the HELLP syndrome (hemolysis, elevated liver enzyme levels and low platelet counts) [9]. In the patients with a history of CKD before pregnancy, 15 out of $22(68 \%)$ had preeclampsia. Seven patients presented severe preeclampsia and all belonged to the moderate and severe renal insufficiency groups.

\section{Pregnancy Outcome and Neonatal Complications}

As seen in table 4 , the frequency of preterm delivery $(48 \%)$ and cesarean section (71\%) was high, especially in those patients with a history of CKD (63 and 72\%, respectively). The mean birth weight was 3,048 $\pm 853 \mathrm{~g}$ in the 70 live births, but it was much lower $(2,376 \pm 494 \mathrm{~g})$ for the patients with CKD compared with the general population in China (3,200-3,300 g) [10]. However, the inci- dence of small for gestational age infants was high (3167\%). We further compared the Apgar scores among the 3 groups, and they were higher in the group with mild renal insufficiency than in the moderate and severe groups $(p<0.05)$. Four infants were stillborn to patients with CKD before pregnancy. Three of them were born to patients with severe renal insufficiency and 1 to a patient with moderate renal insufficiency. There were 2 neonatal deaths due to prematurity; 1 was delivered at 32 weeks because the mother developed the HELLP syndrome, intracranial thrombosis and eclampsia, and the other was delivered at 21 weeks because of severe maternal preeclampsia. Twenty neonates were admitted to an intensive care nursery, most because of prematurity and intrauterine growth retardation.

\section{Discussion}

The major findings in this study were as follows: (1) the incidence of renal insufficiency during pregnancy was higher than in previous reports both in China [11] and overseas [12]; (2) maternal complications were frequent and included a high risk of hypertension and highgrade proteinuria, especially in patients with moderate to severe renal insufficiency; (3) pregnancy is associated with a risk of deterioration of renal function in patients 
with an Scr concentration higher than $70 \mu \mathrm{mol} / \mathrm{l}$, and (4) obstetrical complications, including premature delivery and low birth weight, were common in pregnant women with renal insufficiency.

Major changes in renal function occur during pregnancy, including renal hemodynamics, glomerular and tubular function and endocrine function. For normal pregnant women, renal blood flow increases by $80 \%$ and GFR increases by $50 \%$ in the early period of pregnancy $[1$, 13]. Correspondingly, the Scr concentration falls by $10 \%$ in the early period and $30 \%$ in late pregnancy. This change lasts through the entire course of pregnancy and ends after delivery, i.e. the mean Scr concentration decreases from 70 to $47 \mu \mathrm{mol} / \mathrm{l}$. Therefore, during pregnancy, $\mathrm{Scr}$ $>70 \mu \mathrm{mol} / \mathrm{l}$ is highly suggestive of renal impairment [3]. The value of $70 \mu \mathrm{mol} / \mathrm{l}$ was used to screen for renal insufficiency in the current study. The incidence of chronic renal disease in pregnancy is generally neglected as being low, ranging between 0.002 and $0.01 \%$ in various studies $[12,14-16]$. However, in the current study, the incidence of renal insufficiency during pregnancy was nearly $2.51 \%$. Twenty-two of these patients $(0.73 \%)$ had a history of kidney disease before pregnancy. One of the possible reasons for the higher rate in our study is that we used a much stricter value ( $\mathrm{Scr}$ concentration $>70 \mu \mathrm{mol} / \mathrm{l}$ ) to screen patients. Another concerns the location of our hospital in the southwest area of Shanghai with a population of approximately 5,000,000. Our hospital is the only general hospital in the area, which makes it a priority for the majority of patients with pregnancy-related diseases. It is important to realize that the incidence of renal insufficiency in pregnancy is probably underestimated for several reasons. Firstly, most renal diseases cannot be easily diagnosed and are often neglected in basic medical units $[17,18]$. Secondly, pregnant women whose Scr concentration is higher than $70 \mu \mathrm{mol} / \mathrm{l}$ are often ignored by clinicians, who do not warn them of possible kidney impairment. Thirdly, it is known that pregnancy losses are more likely in the setting of CKD. Early pregnancy losses may not always be noticed by the mother or captured by studies.

Transient increases in proteinuria are common during normal pregnancy $[3,19]$ and even more pronounced during pregnancy complicated by CKD [20]. We found that the mean values of proteinuria of the 3 groups were all over $3 \mathrm{~g} /$ day. While there were no statistically significant differences between the groups, the incidence of severe proteinuria for patients with $S c r<123 \mu \mathrm{mol} / \mathrm{l}$ was lower than for those with $\mathrm{Scr}>124 \mu \mathrm{mol} / \mathrm{l}(\mathrm{p}=0.02)$. Generally, proteinuria not only reflected the degree of re- nal insufficiency but also served as an important index for the prognosis. Some published evidence implies that patients whose urinary protein is over $1 \mathrm{~g} /$ day tend to develop decreased GFR more easily, thereby doubling the risk that patients of this category would progress to ESRD $[21,22]$. In a recent 27 -year prospective study, Imbasciati et al. [23] confirmed that proteinuria with protein greater than $1 \mathrm{~g} /$ day before conception predicted poor maternal and fetal outcomes. Serum albumin falls to $30-35 \mathrm{~g} / \mathrm{l}$, physiologically, before delivery. We also noticed that those patients with moderate to severe renal insufficiency manifested hypoalbuminemia during pregnancy, and we believe that this was due to the high incidence of proteinuria. Hemoglobin levels showed that patients whose Scr concentration was below $123 \mu \mathrm{mol} / \mathrm{l}$ normally did not have anemia, even though $50 \%$ of patients may have some degree of anemia during pregnancy in the general population.

In the present study, we also found that hypertension was common among patients with moderate to severe renal disease. For patients with Scr $<123 \mu \mathrm{mol} / \mathrm{l}$, blood pressure control was better than for those with Scr $>124$ $\mu \mathrm{mol} / \mathrm{l}$. These findings agree with previous reports that hypertension is present in more than $50 \%$ of pregnant women with moderate to severe kidney disease $[4,16]$. The development of hypertension portends a greater likelihood of GFR deterioration [24]. Others have found hypertension to be an independent predictor of maternal GFR decline and ESRD $[22,25]$. Our data showed that MAP increased by $23 \mathrm{~mm} \mathrm{Hg}$, accompanied by a deterioration of renal function, from the first to the third trimester in a subgroup of patients (most of whom had moderate or severe renal insufficiency). However, as this was a retrospective analysis, we were unable to follow up postpartum blood pressure and renal function.

One of the central issues in pregnant women with renal insufficiency is the effect of pregnancy on the course of maternal kidney disease. Current recommendations are that if functional loss is below $50 \%$, stated in most texts to be an Scr concentration equal to or less than 1.4 $\mathrm{mg} / \mathrm{dl}(123 \mu \mathrm{mol} / \mathrm{l})$, the gestation should succeed and should not adversely influence the mother's renal prognosis, though the rate of complications such as preeclampsia and premature birth are increased [26, 27]. Only 2 patients with mild renal injury in this study showed slight deterioration in GFR during pregnancy, and the Scr returned to the value before pregnancy. However, the records of many of the patients with mild renal impairment were inadequate, and this group needs further evaluation. The GFR in 4 out of 14 patients decreased 
severely (over 25\%), and 1 patient entered ESRD after delivery. All 4 patients had Scr over $200 \mu \mathrm{mol} / \mathrm{l}$ in the first trimester. These findings agree with previous reports. Jones and Hayslett [4] reported that there was a rapid progression to ESRD within 6 months after delivery in 10\% of patients with moderate to severe renal injury. However, after exclusion of the women with rapid progression to ESRD, the postpartum Scr concentrations at 12 months were approximately the same as before pregnancy. They concluded that the risk of accelerated progression to ESRD was highest when the Scr concentration was above $2.0 \mathrm{mg} / \mathrm{dl}(167 \mu \mathrm{mol} / \mathrm{l})$ at the beginning of pregnancy. The observation of Imbasciati et al. [23] is encouraging; while as a whole their group of patients lost function during gestation, the rate of functional loss was not affected by the pregnancy, being similar prepartum and postpartum.

Our data demonstrated that the incidence of preeclampsia is high in patients with renal insufficiency (49\%), especially in those with moderate to severe renal insufficiency. Also, in patients with antecedent renal disease, the occurrence of preeclampsia is common (68\%). It is known that renal disease is a potential risk factor for preeclampsia $[28,29]$. We found that the incidence of preeclampsia in those patients with mild renal injury was much higher $(42 \%)$ than that in the general population. Since blood pressure is not known in most patients with mild renal insufficiency, it is difficult to diagnose chronic hypertension or superimposed preeclampsia [7]. It remains to be determined if preeclampsia is related to mild renal injury per se or chronic hypertension. However, the incidence of preeclampsia in this study was quite common regardless of preexisting renal disease. We hypothesize that one of the reasons is that renal function is not routinely tested in the obstetric department in our hospital. Only those patients with manifestation of preeclampsia or suspicion of preeclampsia undergo renal function testing.

It has been shown that women with renal function impairment are at risk of adverse fetal outcomes (e.g. prematurity, low birth weight and neonatal death) [29]. With the advances in perinatal care achieved in the last decades, the prognosis for infants born to women with mild renal injury is good, and the rate of live births is the same as for the general population [30]. Using logistic regression and receiver operating characteristic analysis, Imbasciati et al. [23] confirmed that creatinine levels of 1.4 $\mathrm{mg} / \mathrm{dl}$ or less $(\leq 123 \mu \mathrm{mol} / \mathrm{l})$ were associated with live infant outcomes similar to the pregnant population as a whole, and they went on to demonstrate a cut-off value for creatinine of $1.1 \mathrm{mg} / \mathrm{dl}(97 \mu \mathrm{mol} / \mathrm{l})$, above which the premature birth rate rose significantly. Our data demonstrate that this view still holds true. Even though the incidence of preterm delivery and small for gestational age infants was high in the total series and in those with kidney disease, the Apgar scores of the infants born to women in the mild renal injury group were good. All the stillbirths and neonatal deaths occurred in infants born to women with moderate and severe renal insufficiency, regardless of antecedent renal disease.

Our study has limitations that must be pointed out. Firstly, our study is retrospective in design and relied on patient records. A precise characterization of the frequency of different kidney diseases in this setting is challenging and compromised by a lack of detail and specificity. Secondly, the study was conducted at a single center, thus limiting the generalizability of the conclusions. Thirdly, lack of follow-up of the patients leads to uncertainty about the natural history of the children born to these mothers with renal insufficiency and the effect of pregnancy on the long-term progression of kidney disease.

In conclusion, pregnancy-associated renal insufficiency is not rare. As the delivery approaches, renal function changes accordingly, and pregnant women with renal impairment have a much higher chance of developing preeclampsia. Fetal outcome is strongly related to the mother's renal function and level of proteinuria. We recommend that renal function tests be a routine part of prenatal examinations. Those women with Scr levels above $70 \mu \mathrm{mol} / \mathrm{l}$ should have an early referral to a nephrologist to assess the risks and should have adequate monitoring of obstetric and renal parameters. They should also be referred to centers where cooperation between nephrologists and obstetricians is available.

\section{Acknowledgements}

Tao Xing is supported by a Macquarie Research Excellence Scholarship. This work was supported by the Scientific Research Project of the Shanghai Municipal Health Bureau (2008Y034). The authors wish to thank Professor Christopher R. Bellenger (University of Sydney, N.S.W., Australia) for his help with the manuscript. 


\section{References}

1 Davison JM, Dunlop W: Renal hemodynamics and tubular function normal human pregnancy. Kidney Int 1980;18:152-161.

$\checkmark 2$ Duvekot JJ, Cheriex EC, Pieters FA, Menheere PP, Peeters LH: Early pregnancy changes in hemodynamics and volume homeostasis are consecutive adjustments triggered by a primary fall in systemic vascular tone. Am J Obstet Gynecol 1993;169:13821392.

3 Krane NK, Hamrahian M: Pregnancy: kidney diseases and hypertension. Am J Kidney Dis 2007;49:336-345.

$\checkmark 4$ Jones DC, Hayslett JP: Outcome of pregnancy in women with moderate or severe renal insufficiency. N Engl J Med 1996;335:226232.

5 Mitch WE, Walser M, Buffington GA, Lemann J Jr: A simple method of estimating progression of chronic renal failure. Lancet 1976;ii:1326-1328.

6 Hughes EC: Obstetric-Gynecologic Terminology, with Section on Neonatology and Glossary of Congenital Anomalies. Philadelphia, F.A. Davis, 1972, p 423.

7 Sibai BM: Treatment of hypertension in pregnant women. N Engl J Med 1996;335: 257-265.

$\checkmark 8$ National Kidney Foundation: K/DOQI clinical practice guidelines for chronic kidney disease: evaluation, classification, and stratification. Am J Kidney Dis 2002;39:S1-S266.

-9 Weinstein L: Syndrome of hemolysis, elevated liver enzymes, and low platelet count: a severe consequence of hypertension in pregnancy. Am J Obstet Gynecol 1982;142:159167.

10 Capital Institute of Pediatrics, Coordinating Study Group of Nine Cities on the Physical Growth and Development of Children: Growth standardized values and curves based on weight, length/height and head circumference for Chinese children under 7 years of age. Chin J Pediatr 2009;47:173178.
11 Qiu S: Clinical analysis of the outcome of pregnancy with chronic renal disease (in Chinese). Zhonghua Fu Chan Ke Za Zhi 1993;28:595-598, 634-635.

12 Trevisan G, Lopes Ramos JG, Martins-Costa S, Guardao Barros EJ: Pregnancy in patients with chronic renal insufficiency at Hospital de Clínicas of Porto Alegre, Brazil. Ren Fail 2004;26:29-34.

13 Sturgiss SN, Dunlop W, Davison JM: Renal haemodynamics and tubular function in human pregnancy. Baillieres Clin Obstet Gynaecol 1994;8:209-234.

14 Modena A, Hoffman M, Tolosa JE: Chronic renal disease in pregnancy: a modern approach to predicting outcome. Am J Obstet Gynecol 2006;193:S86.

15 Fischer MJ, Lehnerz SD, Hebert JR, Parikh $\mathrm{CR}$ : Kidney disease is an independent risk factor for adverse fetal and maternal outcomes in pregnancy. Am J Kidney Dis 2004 43:415-423.

16 Cunningham FG, Cox SM, Harstad TW, Mason RA, Pritchard JA: Chronic renal disease and pregnancy outcome. Am J Obstet Gynecol 1990;163:453-459.

17 Akbari A, Swedko PJ, Clark HD, Hogg W, Lemelin J, Magner P, Moore L, Ooi D: Detection of chronic kidney disease with laboratory reporting of estimated glomerular filtration rate and an educational program. Arch Intern Med 2004;164:1788-1792.

18 McClellan WM, Knight DF, Karp H, Brown WW: Early detection and treatment of renal disease in hospitalized diabetic and hypertensive patients: important differences between practice and published guidelines. Am J Kidney Dis 1997;29:368-375.

19 Higby K, Suiter CR, Phelps JY, Siler-Khodr T, Langer O: Normal values of urinary albumin and total protein excretion during pregnancy. Am J Obstet Gynecol 1994;171:984989.

20 Katz AI, Davison JM, Hayslett JP, Singson E, Lindheimer MD: Pregnancy in women with kidney disease. Kidney Int 1980;18:192-206.
21 Jungers P, Chauveau D, Choukroun G, Moynot A, Skhiri H, Houillier P, Forget D, Grunfeld JP: Pregnancy in women with impaired renal function. Clin Nephrol 1997;47: 281-288.

22 Jungers P, Houillier P, Forget D, Labrunie M, Skhiri H, Giatras I, Descamps-Latscha B: Influence of pregnancy on the course of primary chronic glomerulonephritis. Lancet 1995;346:1122-1124.

23 Imbasciati E, Gregorini G, Cabiddu G, Gammaro L, Ambroso G, Del Giudice A, Ravani P: Pregnancy in CKD stages 3 to 5 : fetal and maternal outcomes. Am J Kidney Dis 2007; 49:753-762.

24 Imbasciati E, Ponticelli C: Pregnancy and renal disease: predictors for fetal and maternal outcome. Am J Nephrol 1991;11:353-362.

25 Chapman AB, Johnson AM, Gabow PA: Pregnancy outcome and its relationship to progression of renal failure in autosomal dominant polycystic kidney disease. J Am Soc Nephrol 1994;5:1178-1185.

26 Davison JM, Baylis C: Pregnancy in patients with underlying renal disease; in Davison AM, Cameron JS, Grunfeld JP (eds): Oxford Textbook of Clinical Nephrology. Oxford, Oxford University Press, 2005, pp 22432260

27 Davison JM, Lindheimer MD: Renal disorders; in Creasy RK, Resnik R, Iams J (eds): Maternal-Fetal Medicine: Principles and Practice. Philadelphia, Saunders, 2004, pp 901-924.

28 Duckitt K, Harrington D: Risk factors for pre-eclampsia at antenatal booking: systematic review of controlled studies. BMJ 2005; 330:565.

29 Fischer MJ, Lehnerz SD, Hebert JR, Parikh $\mathrm{CR}$ : Kidney disease is an independent risk factor for adverse fetal and maternal outcomes in pregnancy. Am J Kidney Dis 2004; 43:415-423.

30 Fischer MJ: Chronic kidney disease and pregnancy: maternal and fetal outcomes. Adv Chronic Kidney Dis 2007;14:132-145. 